\title{
AMÉRICA LATINA EN LA VALORIZACIÓN MUNDIAL DEL CAPITAL
}

\section{Jaime Osorio*}

RESUMEN: Tras agudas derrotas al movimiento popular y el contar con abundante mano de obra disponible, el capital ha puesto en marcha una serie de medidas, como la segmentación productiva, auge del capital financiero y ficticio, revoluciones tecnológicas y nuevos patrones de reproducción del capital, con el fin de contrarrestar la caída de la ganancia y encontrar una salida a la crisis. América Latina ha regresado a su vieja condición de región productora de materias primas y alimentos, favoreciendo ahora a China el paso a la plusvalía relativa como forma dominante de generación de valor. Su contracara es la agudización de los procesos de superexplotación en nuestra región.

Pala Bras ClAVE: valorización del capital, superexplotación, biopoder, América Latina, China.

* Docente-investigador del Departamento de Relaciones Sociales de la Universidad Autónoma Metropolitana-Xochimilco, México. 
ABSTRACT: Following key defeats by popular movements, and having abundant labor power at its disposition, capital has put into action a series of measures, such as segmented production, a rushed expansion of financial and fictitious capital, technological advancements, and new patterns of capital reproduction, in order to counteract falling rates of profit and to search for a way out of crisis. Latin America has returned to its previous condition as a region that produces raw materials and agricultural products, giving way to China's status as leader in creating relative surplus value. The hidden side of this effort is a process of overexploitation in our region.

KEY WORDS: capital development, overexploitation, biopower, Latin America, China. 


\section{INTRODUCCIÓN}

\section{A}

nte la caída de la tasa de ganancia desde los años setenta del siglo xx y la larga crisis mundial, el gran capital establece un encadenamiento de procesos de muy variada naturaleza que tienen como hilo conductor recuperar dicha tasa y descargar las pérdidas sobre clases sociales, regiones y capitales diversos.

Estos procesos reclaman una mayor supeditación del trabajo al capital, como también de territorios, espacios y recursos naturales, en niveles nunca vistos, tanto en magnitud como en intensidad.

Además se requiere del incremento de los intercambios y movimientos de mercancías a nivel global, de la expansión del capital financiero y del capital especulativo, y de sus desplazamientos por todos los circuitos del sistema mundial.

A este conjunto de procesos, que abren un nuevo estadio de supeditación del trabajo, territorios, espacios y recursos naturales al capital, le llamamos mundialización.

Entre los procesos que permiten este nuevo estadio de dominio del capital se deben mencionar los siguientes.

\section{PROFUNDA DERROTA POLITTICA DEL MUNDO DEL TRABAJO FRENTE AL CAPITAL}

1. Aquí destacan los golpes militares y el establecimiento de gobiernos autoritarios que aplican políticas de contrainsurgencia en América Latina, desde los años sesenta (golpe militar en Brasil) o los años cuarenta (bogotazo y muerte de Gaitán en Colombia), con grandes costos humanos y políticos para las organizaciones políticas de izquierda; para las organizaciones revolucionarias, sindicales y movimientos sociales; para el campo teórico y la lucha ideológica.

2. Mención especial merece el derrocamiento de Salvador Allende en Chile (1973), que pone fin a un periodo prerrevolucionario, el inicio de una agresiva y prolongada contrarrevolución y el comienzo de la 
aplicación de políticas neoliberales en el planeta (1975), bajo la dictadura de Augusto Pinochet, por parte de su equipo económico conocido como los Chicago boys. ${ }^{2}$

3. También se debe señalar la seria derrota de los trabajadores mineros del carbón en Inglaterra, Gales y Escocia, con más de 200 mil trabajadores en una larga huelga de casi un año (1984), bajo el gobierno de Margaret Thatcher, lo que permite proseguir la marcha de las políticas neoliberales, las que se extenderán muy rápidamente también a Estados Unidos bajo el gobierno de Ronald Reagan, y posteriormente a otras partes del planeta.

4. Estas políticas implicaron la venta de numerosas y en muchos casos redituables empresas estatales al capital privado (para fortalecer la concentración y la acumulación del capital, por la vía del despojo de bienes públicos o comunes), y el desmantelamiento de las prestaciones sociales (que implicaron un brutal despojo del salario real para millones de trabajadores).

5. Pero, sobre todo, en América Latina las políticas y ajustes neoliberales fueron la continuación de las políticas de contrainsurgencia, en su dimensión política, atomizando y desintegrando a la población trabajadora, agudizando el individualismo y la competencia en el seno del mundo del trabajo, alentando la multiplicación de sindicatos en una misma empresa, incrementando el temor a perder el trabajo y, con ello, alentando la desmovilización.

\section{EXTRAORDINARIO INCREMENTO DE LA FUERZA DE TRABAJO DISPONIBLE}

1. Este proceso se ve alimentado por el sustantivo incremento de las mujeres en el mercado de trabajo. La fuerza de trabajo femenina a

\footnotetext{
${ }^{2}$ Estudiantes egresados mayoritariamente de la Escuela de Economía de la Universidad Católica y que realizan posgrados en la Universidad de Chicago, desde finales de los años sesenta, en donde enseña Milton Friedman, entre otros neoliberales.
} 
escala mundial pasó de mil millones, en 1993, a mil 200 millones en el 2003 (oit, 2005).

2. También por el elevado monto del trabajo infantil. Para 1995, el número de niños entre 5 y 14 años económicamente activos ascendía a 250 millones, concentrados fundamentalmente en Asia (153 millones) y África (80 millones). En América Latina la cifra de niños laborando en aquel año era de 17 millones (oIT, 1999). ${ }^{3}$

3. Por el derrumbe del socialismo real y el ingreso al mercado laboral más dinámico de miles de trabajadores altamente calificados (ingenieros, científicos de todas las ramas y trabajadores y obreros con elevada preparación). Muchos miles de estos trabajadores salen y se integran de manera preferente a las economías de la Unión Europea y Alemania en particular.

4. Por la inserción plena de China al mercado mundial, añadiendo casi 800 millones de trabajadores a las necesidades de valorización del capital, la mayoría con muy bajos salarios en dinero y extensas jornadas. Para 2012 la PEA china (considerando a los mayores de 15 años) ascendía a $787^{\prime} 632,272$ trabajadores (oIT, 2012).

\section{Migraciones de la periferia al centro}

Este masivo incremento de la oferta de brazos disponibles también se ve potenciado por procesos migratorios de la periferia a los centros imperialistas.

1. Para 2003, el Consejo Nacional de Población (Conapo) en México calculaba en 390 mil los mexicanos que migraban anualmente a Estados Unidos. Para ese mismo año ya residían en Estados Unidos 26.7 millones de mexicanos. De ellos, 9.9 millones habían nacido

${ }^{3}$ Para 2004, siempre según datos de la oiт, la cifra total habría descendido a los 191 millones de niños entre 5 y 14 años económicamente activos. De ese total, 74 millones realizaban trabajos peligrosos. 
en México, siendo el resto hijos de mexicanos nacidos en Estados Unidos (Conapo, s/f: 32).

2. La población centroamericana en Estados Unidos subió de 345,655 en 1980, a un millón 220 mil para 1990, siendo para 2009 de 2 millones 915 personas, esto es, más que doblan para este último año las cifras de 1980.

3. Para 1997 los inmigrados a la Unión Europea sumaban 10’608,594 personas, los que provenían principalmente del Magreb (Argelia, Marruecos y Túnez), con 2'262,200 personas; de Rusia, 1'799,474; del este y centro de Europa, con 642,105; y del resto del mundo, 4'608,594 personas, principalmente turcos, y en menor medida latinoamericanos (Ahijado et al., 2004). ${ }^{4}$

4. Alemania es de lejos la economía que alcanza mayores ventajas de este proceso, ya que percibió una entrada de inmigrantes anuales por encima del millón y medio en 1989 (año de la caída del muro de Berlín), 1990 y 1992, y por encima del millón en 1991, 1993, 1994 y 1995 (Ahijado et al., 2004: 19). De ese total, poco más o poco menos de 50 por ciento provenían de Europa Oriental y Central, fuesen polacos, rumanos, checos, húngaros y búlgaros, con cifras muy por encima del resto de los países miembros de la Unión Europea (Delgado, 2002). ${ }^{5}$ Para 1999, 29 por ciento de los extranjeros en el país eran turcos.

¿Qué puede significar, desde la valorización del capital, este enorme incremento de trabajadores en el mercado laboral, en tan corto plazo?

${ }^{4}$ La Unión Europea es la región del planeta que más inmigrados ha recibido en los últimos años. Entre 1997 y 2008 llegaron a su territorio 14 millones de inmigrados (http://www.publico,es/ detalle-imagen/305978/?c= Consultado el 7 de octubre de 2014).

${ }^{5}$ Durante los años noventa y a principios del nuevo milenio, los principales destinos de la migración laboral legal de Polonia fueron Alemania (alrededor de 200 mil polacos encontraban empleo anualmente), seguido de Estados Unidos, con 180 mil y Canadá con 50 mil trabajadores polacos anuales. Pero las cifras se incrementan una vez que Polonia ingresa a la Unión Europea. Entre 2004 y 2007, a lo menos dos millones de trabajadores polacos han emigrado y conseguido empleo (Kazmierkiewicz, 2008: 35). Para 1996, Alemania había recibido 276,753 polacos, 109,265 rumanos y 59,112 checos, entre los más importantes de Europa del Este y Centro (Ahijado et al., 2004:19). 
En los hechos es una enorme acumulación «originaria», ya que millones de los nuevos vendedores de fuerza de trabajo fueron expropiados de los medios de producción estatales, como ocurrió con los trabajadores de la antigua Unión Soviética, al reconvertirse esas economías al capitalismo.

Una vez colapsado el llamado socialismo real, la propiedad común o la propiedad estatal de esos medios de producción pasa ahora a manos de la antigua burocracia estatal y partidaria, la que se enriquece muy rápidamente con la adjudicación de grandes y rentables empresas (caso paradigmático es el de las petroleras), vendidas prácticamente a precios de regalo.

En el caso chino, si bien las empresas estatales no fueron vendidas, ni tampoco la tierra, se permitió el inicio de actividades del capital en un sinnúmero de actividades productivas y de comercio, y ante la escasez de bienes indispensables y de apoyos para el campo, en las ciudades la población comenzó a ingresar al régimen capitalista que se expandía, abandonando de manera creciente las tierras y alentando el incremento de la población urbana, a pesar de las restricciones. La rápida conversión de China en «fábrica mundial» fue posible a partir de estos procesos, alimentados por la escasez de medios de vida y de condiciones de producción en el campo que permitieran una vida digna.

\section{Incremento de la superpoblación relativa}

El agudo incremento de fuerza de trabajo en el mercado mundial abrió las puertas para un acelerado incremento de la superpoblación relativa.

1. Por el traslado de actividades productivas a China y el cierre de plantas en las economías y ciudades en que esas actividades son abandonadas, creándose ciudades fantasmas, como Detroit en Estados Unidos, antigua cuna de la producción de automóviles, lo que elevó el desempleo. 
2. En otros casos, la elevada producción de productos de todo tipo en China, con mano de obra educada, pero con bajas tecnologías (industrias de telas y bordados, del juguete, de artesanías etcétera), provocó la quiebra de industrias instaladas en otras economías (caso de manteles y otros productos de tela bordados en Aguascalientes, México), alentando mayor desempleo.

3. Esta enorme masa de población excedente que se fue creando a lo largo y ancho del sistema mundial, favoreció las presiones y descensos de los salarios (alentados a la baja también por los bajos salarios en China en los años ochenta y noventa del siglo $\mathrm{xx}$ ), la reducción de las prestaciones sociales, prolongaciones de la jornada y de la intensidad del trabajo.

4. De esta forma el capital sumó en las últimas cuatro décadas nuevos elementos para imponer regímenes de superexplotación, ${ }^{6}$ al calor de la crisis, en muchas más regiones que las dependientes. ${ }^{7}$

5. Efectos en la misma dirección propició el incremento del trabajo femenino y el trabajo infantil. En las maquilas los hombres fueron desplazados por trabajadoras que perciben salarios inferiores, a pesar de laborar con mayor calidad. También ocurrió lo anterior allí en donde niños y adolescentes realizan ahora el trabajo anteriormente desarrollado por adultos, como coser balones de futbol, producir ladrillos o tabiques de barro, o en labores de cosecha en el campo.

6. De acuerdo con la Organización Internacional del Trabajo (огт), el desempleo mundial pasó de 219 a 241 millones de trabajadores entre 2007 y 2009, en tanto el empleo vulnerable ascendió a cerca de 50 por ciento del total del empleo para 2014 (огт, 2014).

7. Esto creó condiciones para que el capital despliegue agudas formas de explotación y superexplotación. Procesos como la subcontratación, la precarización y la informalidad toman forma aguda. Por otro lado, reverdecen formas como la esclavitud y la semiesclavitud.

${ }^{6}$ Esto es, de procesos de explotación en que se viola el valor de la fuerza de trabajo (Marini, 1973). ${ }^{7}$ Sobre las formas de superexplotación y su presencia y consecuencias diferenciadas en el capitalismo desarrollado y en el dependiente, véase Osorio (2013). 
8. Nunca como en estas últimas cuatro décadas el capital contó con tan abundante y calificada mano de obra para sus procesos de expansión y de supeditación real del trabajo al capital; y para poner en marcha los más feroces procedimientos de explotación y superexplotación sobre tan amplia población a nivel de todo el sistema mundial capitalista.

\section{CUARTA REVOLUCIÓN TECNOLÓGICA}

1. Los sustanciales avances en conocimientos y en tecnologías en el campo de la microelectrónica, la biotecnología, la genética, las nanotecnologías y en nuevos materiales permiten hablar de una cuarta revolución científica y tecnológica, proceso que abre nuevos campos a las inversiones y operaciones del capital.

2. Estos procesos modifican las dimensiones espacio/temporales, permitiendo que se reduzcan.

3. Los avances en comunicaciones permiten el control de procesos de trabajo y de circulación de mercancías y dinero en tiempo real, en cualquier lugar del mundo.

4. La generación de nuevos materiales, más livianos pero más resistentes, favorece la generación de aviones y barcos más grandes, lo que elevará la capacidad de traslado de mercancías por el mundo.

\section{SEGMENTACIÓN PRODUCTIVA Y CADENAS GLOBALES}

1. Estos avances científicos y tecnológicos están en la base que permite la segmentación de los procesos productivos, esto es, la separación de las distintas fases o etapas de la producción de bienes, y su dislocación en diversas regiones y economías del planeta, buscando aprovechar la abundancia de trabajo barato, sea calificado o semicalificado. 
2. Los avances tecnológicos permiten también, como ya hemos indicado, el masivo incremento de la circulación de mercancías. Para acercarnos a la expansión de los movimientos mercantiles podemos considerar la situación de los cinco puertos que manejan la mayor cantidad de contenedores para 2004 y 2011: Shangai, en China (que pasó de 14.5 a 31.7 millones de Teus ${ }^{8}$ en los años señalados); Singapur, en Singapur (de 21.3 pasó a 29.9 millones); Hong Kong, en Hong Kong (de 21.9 a 24.3 millones); Shenzhen, en China (de 13.6 a 22.5 millones), y Busan, en Corea del Sur (de 11.4 a 16.1 millones de TEus) (Journal of Commerce, 2012). ${ }^{9}$

3. Cadenas globales de producción y de comercialización, con grandes capitales y marcas a la cabeza son las que organizan y distribuyen segmentos por el planeta. Desde grandes fábricas hasta pequeños talleres se han debido someter a las decisiones de estas cadenas globales, por su control del mercado y de la tecnología, produciendo en cadenas de subcontratación para las grandes marcas.

4. Mientras más abajo nos encontremos en las cadenas de subcontratación, más reducidas serán las ganancias de los capitales, pero también más precarias y violentas serán las condiciones de trabajo de los obreros que allí se ubican.

\section{NUEVA DIVISIÓN INTERNACIONAL DEL TRABAJO}

1. La revolución tecnológica y la segmentación de los procesos productivos han hecho posible una nueva división internacional del trabajo (NDIT).

\footnotetext{
${ }^{8} \mathrm{El}$ Teus es una unidad de medida que equivale a 20 pies.

${ }^{9}$ En América Latina los cinco principales puertos que manejan contenedores, para 2010, son Colón, Panamá (2.8 millones teus); Balboa, Panamá (2.7 millones); Santos, Brasil (2.7 millones); Kigston, Jamaica (con 1.8 millones) y Buenos Aires, Argentina (con 1.7 millones). Disponible en www. legiscomex con datos de CEPAL.
} 
2. En esta NDIT, los países centrales monopolizan aquellos segmentos productivos que reclaman elevados conocimientos y tecnología, como el diseño general de bienes y la producción de partes sofisticadas, así como las políticas de comercialización y del marketing.

3. Los segmentos con un mayor peso del trabajo y con débiles requerimientos tecnológicos y de conocimientos son los que se instalan a su vez en forma predominante en las economías y regiones dependientes.

4. Para América Latina, lo más significativo de la NDIT tiene que ver con su regreso, en nuevas condiciones, a lo que fueron sus orígenes en su inserción al mercado mundial capitalista, en tanto región productora de materias primas y alimentos.

5. Esta situación es acompañada, en pocas economías, como la mexicana y brasileña, con la presencia de algunos segmentos industriales referidos a la producción de partes, en industrias de bienes durables, y también en otras economías, de maquila y ensamble en la de bienes industriales no durables.

6. Con esto, el proyecto de industrialización, en tanto proyecto que cubriera desde bienes de fácil producción hasta bienes intermedios y más tarde máquinas y herramientas, es definitivamente abandonado en la región. Ahora lo que predomina es la presencia de algunos segmentos industriales y no la de un proyecto orgánico y general de industrialización.

\section{NUEVO PATRÓN DE REPRODUCCIÓN DEL CAPITAL}

1. Con estos cambios se puso fin al antiguo patrón industrial de reproducción del capital y se abrió paso a un nuevo patrón en la región: el exportador de especialización productiva (Osorio, 2012).

2. Este nuevo patrón es mucho más que una simple nueva forma de reproducción del capital. Es la forma que asume la reproducción del capital en América Latina en un estadio del capital mundial de 
supeditación real del planeta mismo, de la naturaleza y de la población trabajadora a la lógica y necesidades del capital. El sometimiento y la subordinación del mundo y de todo lo existente, material y simbólico, a esa lógica ha alcanzado niveles inusitados.

3. Con la puesta en marcha del nuevo patrón de reproducción nunca fue más real la condición de sujeto del capital, en tanto valor que organiza, crea y recrea las condiciones para su despliegue y reproducción en tanto valor que se valoriza.

4. También nunca fue más real para los trabajadores que su fuerza creadora, en tanto fuerza apropiada por el capital, se establece frente a ellos como un poder ajeno y enajenante (Marx, 1975: XXVII).

5. Y nunca fue más real para América Latina su condición de reservorio fundamental de la valorización del capital a nivel mundial.

\section{SÍNTESIS PRELIMINAR}

1. Con los golpes militares, las políticas de contrainsurgencia, la debacle del socialismo real y el abandono de un proyecto socialista en China, nunca la politica fue tanta economía.

2. Por otro lado, con la puesta en marcha de las políticas neoliberales, la segmentación y dislocación de los procesos productivos, la puesta en marcha de una nueva división internacional del trabajo y el nuevo patrón de reproducción, nunca la economía fue tanta politica.

\section{AMÉRICA LATINA Y LA VALORIZACIÓN DE CAPITAL EN CHINA EN TORNO A LA PLUSVALÍA RELATIVA}

1. La región fue vital en el siglo Xix para que el eje de la acumulación en el mundo central pasara de la plusvalía absoluta a la relativa (Marini, 1973: 26-27), con sus masivas exportaciones de alimentos, que permiten elevar la cuota de plusvalía. 
2. América Latina fue fundamental con su producción de materias primas, limitando el crecimiento de la composición orgánica del capital, lo que redundó, junto al primer punto, en morigerar las tendencias a la caída de la tasa de ganancia en el sistema mundial.

3. Todo esto tuvo como contracara en la región el incremento de la dependencia, la transferencia de valor y de la superexplotación, exacerbando la negatividad del capital.

4. Bajo el nuevo patrón de reproducción, ahora en el siglo xxi, América Latina vuelve a jugar un papel de importancia central para el capital mundial y su valorización.

5. Este nuevo papel está estrechamente relacionado con la suerte de la economía china, favoreciendo su conversión en la economía mundial más poderosa, en la última mitad de 2014, desplazando a Estados Unidos.

6. Si para 1979, cuando se inician las reformas económicas en China, que implicó «el proceso de industrialización y de urbanización más intenso que haya conocido la humanidad», el P Ів chino sólo alcanzaba a 9 por ciento de su similar estadounidense (CEPAL, 2011:6), a mediados de 2014 ya supera al de Estados Unidos. ${ }^{10}$

7. Desde antes de 2000, América Latina comenzó a jugar un importante papel en el comercio exterior chino. Pero es entre 2000 y 2010 cuando la región se constituye en la más dinámica en el crecimiento porcentual del comercio exterior de aquel país. Así, de un crecimiento anual de las exportaciones hacia América Latina de 26.8 para 2000-2005, se pasa a 31.0 por ciento para el periodo 2005-2010, casi doblando los crecimientos anuales frente a la Unión Europea y Estados Unidos (CEPAL, 2011: 12).

\footnotetext{
${ }^{10}$ Medido por el «poder adquisitivo» (Purchasing Power Party: PPP) el PIB chino, según el FMI, asciende a 17.6 millones de millones de dólares (trillones para el mundo anglosajón), en tanto el de Estados Unidos llega a los 17.4 millones de millones de dólares (FMI, Perspectiva económica mundial 2014).
} 
8. Las tasas de crecimiento de las importaciones chinas desde América Latina también son las más elevadas frente a cualquier otra región en esos años, pasando de 12.7 por ciento de crecimiento anual para el periodo $1995-2000$, a 27.7 por ciento para el quinquenio 2005-2010, nuevamente por encima del crecimiento sobre las importaciones desde Estados Unidos y la Unión Europea, que les siguen en importancia (CEPAL, 2011: 12).

9. Es relevante hacer notar que a pesar del incremento de los precios de la mayoría de los productos que América Latina exporta, a causa de la elevación de la demanda china, el crecimiento de la economía china no se ve afectada. Por el contrario, es el periodo en que más crece, en cifras de alrededor de 10 por ciento. Y es este dinamismo el que eleva las importaciones desde América Latina.

10. Sin embargo, hasta 2010 existía un desequilibrio en el comercio que favorecía a China, de alrededor de 40 mil millones de dólares, propiciando un déficit comercial de la región con esa economía (CEPAl, 2011: 15). Con el declive de las importaciones chinas en los últimos años, dada la retracción de su crecimiento, es posible que ese déficit tienda a mantenerse o a crecer, si se considera que China es el principal exportador mundial de bienes. ${ }^{11}$

11. ¿Qué es lo que compra China a América Latina? Destacan de manera relevante alimentos y materias primas, los rubros justamente de mayor peso en las exportaciones de la región. En total las exportaciones de materias primas representan 60 por ciento de las exportaciones totales de bienes de la región, como minerales e hidrocarburos. También tienen un peso destacado los alimentos.

12. Para algunas economías de la región, los principales rubros de exportación a China y su porcentaje en el total de las exportaciones de 2007 a 2009 son: Argentina, soja (53.1 por ciento); aceite de

\footnotetext{
${ }^{11}$ Para 2010 China exportaba 10 por ciento de los bienes en el mercado mundial, muy superior al 4 por ciento que exportaba en 2000. Sin embargo, su posición en la exportación de servicios es más baja, de sólo 5 por ciento, por debajo de Estados Unidos, Alemania y Reino Unido (cepal, 2011: 9).
} 
soja (26.5 por ciento); Bolivia, estaño y aleaciones (23.9 por ciento), concentrados de estaño (22 por ciento) y petróleo crudo (12.6 por ciento); Brasil, concentración de hierro (44.9 por ciento), soja (24.2 por ciento), petróleo crudo ( 5.86 por ciento); Chile, cobre (55.4 por ciento), concentrado de cobre (24.2 por ciento); Colombia, petróleo crudo ( 53.8 por ciento), otras ferroaleaciones ( 36.5 por ciento); Ecuador, petróleo crudo ( 94.7 por ciento); Guatemala, azúcar (59.1 por ciento); México, macroconjuntos electrónicos (14.0 por ciento); Paraguay, otros cueros de bovinos (31.6 por ciento), maderas de no coníferas (28.5 por ciento); Perú, concentrado de cobre ( 38.6 por ciento), harinas no comestibles ( 15.7 por ciento); Uruguay, soja (48.1 por ciento), pasta química de madera (23.1 por ciento); Venezuela, petróleo crudo (78.3 por ciento), concentrado de hierro (23.2 por ciento) (CEPAL, 2011:23).

13. China ha elevado su importancia como socio comercial para un gran número de economías de la región. Entre 2000 y 2009, las exportaciones de Argentina a China pasaron del sexto al cuarto lugar. En iguales años, para Brasil, del doceavo pasaron al primer lugar; en Chile, del quinto también al primer lugar; en Costa Rica, del trigésimosexto al sexto y en Perú, del cuarto al segundo lugar.

14. En importaciones, en Argentina, entre 2000 y 2009, China pasó del cuarto al tercer lugar; en Bolivia, del séptimo al cuarto; en Brasil, del decimoprimero al segundo lugar; en Chile, del cuarto al segundo; en Colombia, del noveno al segundo; en México, del séptimo al segundo; en Perú, del noveno al segundo; en Uruguay, del séptimo al segundo y en Venezuela del decimoctavo al tercero (CEPAL, 2011: 19).

15. América Latina ha jugado un papel de primera importancia en los movimientos en el sistema mundial que implican el desplazamiento de Estados Unidos como la principal economía del mundo, aunque ello no signifique su pérdida de hegemonía en el sistema mundial, marcada por su poderío militar, peso del armamento atómico, bases militares por el mundo, avances en ciencia y tecnología, y contar con la moneda universal. 
16. La masiva disposición de alimentos y materias primas desde América Latina ha acelerado los procesos para que China se instale en los umbrales del desarrollo. Pero por sobre todo, América Latina ha favorecido el paulatino incremento del paso de la plusvalía absoluta a la plusvalía relativa en las zonas urbanas chinas, con las exportaciones de alimentos, el incremento del mercado interno por la vía de los aumentos salariales, ${ }^{12}$ y la expansión de la estructura industrial, con las masivas exportaciones de materias primas. ${ }^{13}$

17. Todo ello ha favorecido el aumento de la tasa de plusvalía en la economía china, así como la reducción de la composición orgánica del trabajo, limitando las tendencias a la caída de la tasa de ganancia.

18. A pesar del desfase entre el sector urbano y el sector rural, en donde permanece todavía una enorme masa de trabajadores en las zonas rurales en condiciones precarias, y que han jugado un papel de primera importancia en la inusitada industrialización china, por la vía del traspaso de valores al sector industrial y urbano, China se encuentra en los umbrales del desarrollo, combinando en magnitudes y dimensiones inusitadas, sectores industriales de muy alto desarrollo tecnológico, con sectores de producción de muy baja tecnología y mayor peso del factor trabajo, lo que convierte a esta economía en una feroz competidora tanto con el mundo desarrollado, como con el sector industrial y artesanal del mundo dependiente.

19. El paso al desarrollo implica reforzar las tendencias al ingreso de China a una fase expansiva imperialista, lo que traerá para los capitales en América Latina beneficios en el corto y mediano plazo, por el incremento de los préstamos y de las inversiones. Pero en la medida

\footnotetext{
${ }^{12}$ Los salarios en las zonas urbanas de China se han incrementado por tres, de 2000 a 2010 , particularmente en las empresas estatales y en menor medida en las privadas.

${ }^{13} \mathrm{~A}$ diferencia de Estados Unidos y la Unión Europea, la demanda china de materias primas hacia América Latina es poco diversificada. Se centra en metales (abastecidos por Chile, Perú y en menor medida Brasil). La demanda global china de hierro, cobre, aluminio y carbón, se estima respectivamente cercana a 60, 40, 42 y 45 por ciento (ocDe/CEPAL/CN, 2014: 37-38).
} 
que crezcan las inversiones directas chinas en el exterior, ${ }^{14}$ así como las exportaciones de servicio, y el posible establecimiento de monedas que compitan con el dólar, en donde la moneda china tendrá gran peso, los problemas para la región tenderán a incrementarse.

\section{RECRUDECIMIENTO DE LA SUPEREXPLOTACIÓN}

1. Todos estos importantes movimientos en los cuales ha incidido la economía latinoamericana en el sistema mundial, lo vuelve a hacer redoblando los procesos que marcan su condición de dependencia y subordinación, y redoblando a su vez el fundamento de la dependencia: la superexplotación de los trabajadores, lo que permite incrementar la masa de valor apropiado por el capital local y transnacional, por la vía de elevar el traspaso del fondo de consumo o de vida de los trabajadores al fondo de acumulación del capital.

2. La expropiación de prestaciones sociales en materia de vivienda, salud, educación, jubilaciones, días de descanso, pagos por número de hijos, etcétera, ha implicado apropiaciones a su vez del salario real indirecto y de violaciones al valor total de la fuerza de trabajo $y$ a su fondo de vida.

3. La extensión de las horas diarias de trabajo, prolongadas también por las horas de transporte para llegar a los centros de trabajo, golpean el valor total de la fuerza de trabajo, al igual la generalización de contratos temporales o el empleo sin contratos, y con jornadas laborales con menos horas o con menos días de trabajo semanal, reduce los salarios e incrementa a su vez el subempleo.

4. Una pobre aproximación a la envergadura de estos procesos nos lo señala el hecho de que los salarios directos en la región sufrieron descensos enormes entre los años setenta e inicios de los noventa,

${ }^{14}$ En 2013, esas inversiones llegaron a 90,200 millones de dólares, sólo por debajo de Estados Unidos y Japón. 
para iniciar, en algunas economías, leves recuperaciones en la primera década del siglo Xxi. ${ }^{15}$

5. Con ello las transferencias de valor al exterior se elevan vía transferencia de ganancias, en tanto el capital extranjero participa de las principales empresas exportadoras ligadas a la producción de agroalimentos y la minería. ${ }^{16}$

6. La condición exportadora del nuevo patrón hace factible redoblar la superexplotación, en tanto la producción de los ejes exportadores está alejada del consumo de los trabajadores locales.

7. También debilita la superexplotación la pobre pulsión productivista que caracteriza al capitalismo dependiente. Los focalizados puntos en donde la productividad alcanza alguna elevación ocurren en algunos segmentos de cadenas productivas. Pero dichas innovaciones aparecen altas en relación con el resto de la economía local. Son sin embargo muy bajos en relación con las industrias y segmentos de punta en los centros desarrollados.

\section{BIOPODER Y VIDA EN ENTREDICHO}

1. Para el grueso de la población mundial, trabajar en estos días y en estas condiciones, implica entregar la vida al capital en largas horas de transporte, extensas jornadas laborales y salarios que no permiten reponer energías ni capacidades.

${ }^{15}$ De un índice 100 para 1982 de los salarios reales, Brasil presenta 61 para 1971, para ascender a 75 en 1990. Para iguales años, Argentina pasa de 100 a 73, Chile de 123 baja a 96 y México de 88 desciende a 72 (Weeks, 1999). Considerando las dos principales economías de la región y con el mayor monto de trabajadores, tenemos: en Brasil, el porcentaje de trabajadores que percibían menos del salario mínimo asciende a 30.5 por ciento en 1992 y se mantiene en 27.9 en el 2001. Tras el arribo de Lula da Silva a la Presidencia, los salarios comienzan a remontar levemente (ort, 2009). En tanto, para 2004, en México 23.9 por ciento de los trabajadores perciben menos de un salario mínimo y 22.7 por ciento, entre uno y dos salarios mínimos. Cabe destacar que entre 1970 y 2006 el salario mínimo había perdido poco más de 40 por ciento de su poder adquisitivo (СAм, 2006). ${ }^{16}$ Para 2006, las empresas transnacionales controlan o son propietarias de 30 por ciento de las empresas mineras y de 37 por ciento de las empresas agroindustriales, con lo que sacan cuantiosos beneficios del incremento de los precios mundiales de esos productos en el periodo (CEPAL, 2007). 
2. No tener trabajo, por otro lado, significa quedar condenado a la miseria, a la carencia de asistencia médica, a no contar con alimentos y ropa suficientes, sometidos a una vida indigna de ser vivida.

3. En términos biopolíticos, con la agudización de la superexplotación el capital profundiza a su vez las pulsiones a poner la vida de los trabajadores en entredicho. Es decir, refuerza y manifiesta su poder sobre la vida.

4. Establecida la relación mercantil bajo el supuesto del intercambio de equivalentes entre valor de la fuerza de trabajo y salario, el capital, a espaldas del mercado, y de cara a la producción, lleva a cabo procesos que destruyen y denigran la vida humana.

5. Los trabajadores sufren contaminación por minerales y gases de las profundidades de la tierra, o por ácidos empleados en los procesos de producción, y por insecticidas y plaguicidas a la hora de la cosecha; sin salarios suficientes para cubrir necesidades médicas o alimenticias; sumidos otro gran porcentaje en la miseria y el pauperismo, por el desempleo crónico.

6. Es la vida de los paupers modernos la que queda en entredicho en cualquiera de las formas antes mencionadas. Nunca fue más cierto que hoy el trabajo es sinónimo de muerte, al agotar o cercenar la vida de los trabajadores, activos o inactivos, empleados o desempleados.

7. Según estimaciones de la OIT, «de un total de 2.34 millones de accidentes de trabajo mortales cada año, sólo 321 mil se deben a accidentes. Los restantes 2.02 millones son muertes causadas por diversos tipos de enfermedades relacionadas con el trabajo, lo que equivale a un promedio diario de más de 5,500 muertes» (огт, 2013). ${ }^{17}$

8. Nunca fue más real que el moderno homo sacer (Agamben, 2013), ${ }^{18}$ aquel al que quienquiera puede dar muerte sin ser considerado homicida, lo constituyen los trabajadores en general, ya sea agotando sus fuerzas vitales, atados a maquilas, fábricas, minas, comercios o empresas agroindustriales; o bien elevando el peligro de sus vidas

${ }^{17}$ Disponible en http://ilo.org/americas/temas/dia-mundial-seguridad-y-salud-en -el-trabajo ${ }^{18}$ Para una crítica de su concepción de biopoder y de la de Michel Foucault (Osorio, 2012b: 85-108). 
en masivas migraciones en la búsqueda de una vida digna; o bien condenados al desempleo y al pauperismo.

9. Como en la Francia revolucionaria e ilustrada del siglo xviri, en que se ponderaban las virtudes de la libertad, en momentos en que los imperios coloniales, incluido el francés, se sustentaban sobre el trabajo y la muerte de miles de esclavos (Buck-Morss, 2013), hoy el capital nos habla de los derechos a la vida, de cómo preservarla (no fumar, no comer grasas ni azúcares, hacer ejercicios, etcétera), en los mismos momentos en que diaria y cotidianamente es la muerte o la vida en entredicho de los trabajadores lo que predomina.

\section{TERRITORIOS Y DESPOJO}

1. En la mundialización, y bajo el nuevo patrón de reproducción de capital en América Latina, cada centímetro cuadrado de territorio es considerado un objeto de apropiación por el capital.

2. No sólo porque esos territorios han sido y siguen siendo escudriñados desde los aires por poderosos equipos que develan sus riquezas en la superficie y en las entrañas de la tierra y de los mares.

3. Apropiación, porque enormes extensiones continentales ya están destinadas a generar soja, frutas, maderas, minerales, petróleo, gas, o constituyen inmensas reservas de aguas.

4. En estas nuevas condiciones, el capital lleva a sus extremos la apropiación de tierras y fuentes de agua, expropiando y expulsando a pueblos y comunidades. Con ello agudiza la separación entre los productores y los medios de vida y los medios de producción.

5. El despojo de tierras y de saberes asume en estos tiempos dimensiones inauditas. Millones de paupers desnudos y despojados de todo se ven compulsionados a entrar en relaciones directas con el capital.

6. La libertad de presentarse en el mercado va perdiendo su engañosa ficción, para poner de manifiesto que es la violencia la fuerza que obliga a ponerse a disposición del capital. 


\section{ADIÓS A LA INDUSTRIALIZACIÓN}

1. Con el nuevo patrón, productor de segmentos industriales, maquila, alimentos y materias primas para demandas externas, el capital local manifiesta su abandono de la idea de proyectos de desarrollo industrial autónomos e integrales. Asume así, sin ocultarlo, su condición subordinada a las decisiones de capitales transnacionales que encabezan cadenas globales de producción o comercialización.

2. Las ideas de desarrollo orgánico o desarrollo nacional quedan en la prehistoria y como proyectos frustrados. Con la producción de materias primas y alimentos, la especialización productiva en marcha, con grandes beneficios en la última década, impide preguntar cómo desarrollar nuevos sectores productivos, cómo ganar en conocimientos y tecnologías. Bajo el nuevo patrón exportador se ha incrementado la dependencia y la subordinación de América Latina.

3. Pero la enorme vulnerabilidad que significa sostener un proyecto económico sobre bases tan frágiles pronto mostrará sus resultados. El descenso en el crecimiento de China y la reducción de la demanda de alimentos y materias primas ya se hace sentir en la región.

\section{AUGE DEL CAPITAL FINANCIERO Y ESPECULATIVO}

1. La caída de la tasa de ganancia lanzó a cuantiosos capitales a buscar ganancias fáciles en la esfera financiera y especulativa. Esta tendencia, unida a las nuevas tecnologías de comunicación, han potenciado el poder del capital especulativo, que en tiempo real mueve enormes masas de recursos por casas de bolsa del mundo, comprando y vendiendo papeles gubernamentales, apostando por precios a futuro de materias primas, por el ascenso o caída del valor de acciones de corporaciones, etcétera, en una verdadera economía casino.

2. El enorme peso alcanzado por estos capitales, en donde la privatización de los fondos de pensiones no ha sido ajena, sin regulaciones 
sustantivas, permite elevar las cifras de ingreso de capital en la región y eleva también las notas de las empresas calificadoras. Todo ello deja a estas economías expuestas a los vaivenes especulativos, acrecentando la transferencia de valores e incrementando la volatilidad y la vulnerabilidad.

3. En los últimos años crece, a su vez, el crédito hipotecario y de consumo, aunque intentado evitar las operaciones que llevaron a las burbujas que explotaron en 2008 en Estados Unidos. Pero el riesgo de alcanzar ganancias fáciles mantiene latente esos peligros, incrementados además por el discurso que hace reposar en el incremento del consumo de una supuesta clase media las bondades de un nuevo desarrollismo.

\section{A MODO DE CONCLUSIÓN}

1. Si ya desde el siglo xix, para referirnos al periodo iniciado con los procesos de independencia, la economía latinoamericana jugó un papel central en la valorización del capital mundial y en cambios sustantivos en los ejes de generación de plusvalía, permitiendo el paso de la plusvalía absoluta a la relativa en el mundo central, y frenando las tendencias a la precipitación de crisis, o acelerando su recuperación, en los nuevos tiempos la región vuelve a cumplir un papel de primer orden en esa valorización mundial.

2. Ahora aportando cuantiosos recursos en materia de trabajo y superexplotación para acelerar la recuperación de la tasa de ganancia, al tiempo que con la expansión de sus exportaciones en materias primas y alimentos, permitir en los nuevos tiempos la expansión ahora de la economía china y el paso, también allí, a lo menos en sus sectores industriales urbanos, a sustentar su crecimiento en la plusvalía relativa, favoreciendo con ello la expansión de los mercados internos.

3. La contracara de estos ingentes procesos en América Latina son redoblar los atávicos procesos de subordinación y dependencia, así 
como los centrados en la transferencia de valores al mundo central, y de hacer del fondo de consumo de los trabajadores locales fondos de acumulación del capital. Con ello el capital agudiza su dimensión de barbarie y el autoritarismo para que ellos sean factibles.

4. El pensamiento crítico vive quizá uno de los momentos de menor lucidez. Sólo el trabajo paciente y perseverante nos permitirá estar a la altura de los enormes problemas planteados.

\section{BIBLIOGRAFÍA}

Agamben, Giorgio (2013), Homo Sacer. El poder soberano y la nuda vida, Valencia, Pre-Textos.

Ahijado, Manuel, Armando de Lucas, Juan Martínez y Susana Cortés (2014), Inmigración en la Unión Europea desde una perspectiva global y sus impactos: una evaluación, UNed-IVE, Universidad Complutense y Universidad Politécnica de Barcelona. Versión con ligeras modificaciones del Working Paper 2004.4 del Instituto Virtual Europeo. Disponible en www.european-virtual-institute.org.

Buck-Morss, Susan (2013), Hegel, Haití y la historia universal, México, Fondo de Cultura Económica.

Centro de Análisis Multidisciplinario (САM) (2006), Reporte de Investigación, núm. 70, UNAM.

Cepal (2007), La inversión extranjera en América Latina y el Caribe 2007, Santiago, CEPAL.

(2011), La República Popular China y América Latina en el Caribe. Hacia una nueva fase en el vínculo económico, Santiago, CEPal.

(2013), Panorama de la inserción internacional de América Latina y el Caribe 2013, Santiago, CEPAL.

Consejo Nacional de Población (Conapo) (s/f), La migración mexicana hacia Estados Unidos, núm. 3. Disponible en www.conapo.gob.mx/works/models/ CONAPO/migracion../03a.pdf (consultado el 13 de marzo de 2015).

Delgado Godoy, Leticia (2002), La inmigración en Europa: realidades y políticas, Universidad Rey Juan Carlos, Unidad de Políticas Comparadas, documento de Trabajo 18.

FMI, Perspectiva económica mundial 2014. 
Journal of Commerce (2012), The Joc Top 50 World Container Ports. Disponible en http://.joc.com/sites/default/files/u48783/pdf/Top50-container-2012.pdf

Kazmierkiewicz, Piotr (2008), «Migraciones y redes transnacionales: comunidades inmigradas de Europa Central y del Este en España», Revista СІDов d'Afers Internacionals, núm. 84.

Marini, Ruy Mauro (1973), Dialéctica de la dependencia, México, Serie Popular Era.

MarX, Karl (1971), Elementos fundamentales para la crítica de la economía politica (borrador) 1857-1858, México, Siglo XXI Editores.

(1975), El Capital, México, Siglo XXI Editores.

oCde/CEPAL/Caf (2014), Perspectivas económicas de América Latina 2014. Logística y competitividad para el desarrollo, Santiago, CEPAL.

Organización Internacional del Trabajo (огт) (2005), «El empleo femenino: tendencias mundiales y acciones de la OIT», ponencia de la OIT $49^{a}$ sesión de la Comisión sobre la Condición de la Mujer, Naciones Unidas, Nueva York.

оіт (1999), Datos y cifras sobre el trabajo infantil, Ginebra, oIт.

(2009), Perfil do Trabalho decente no Brasil, Brasil, oIT.

(2013), Día Mundial de la Seguridad y la Salud en el Trabajo 2013. Disponible en http://ilo.org/americas/temas/dia-mundial-seguridad-y-saluden -el-trabajo.

(2014), Población activa, total, página oficial en internet (consultada el 22 de septiembre de 2014).

(2014), World of Work Report 2014: Developing with Jobs, Ginebra, ort.

Osorio, Jaime (2012), «El nuevo patrón exportador de especialización productiva en América Latina», Revista da Sociedade Brasileira de Economía Política, núm. 31.

(2012b), Estado, biopoder, exclusión. Análisis desde la lógica del capital, Barcelona, Anthropos/UAm.

(2013), «Fundamentos de la superexplotación», Razón y Revolución, núm. 25.

Weeks, John (1999), «Salarios, empleo y derechos de los trabajadores en América Latina entre 1970 y 1998», Revista Internacional del Trabajo, vol. 118, núm. 2.

\section{Páginas electrónicas:}

http://www. legiscomex.com

http://www.publico.es/detalle-imagen/305978/?c= 